\title{
Effects of hypotension induced with sodium nitroprusside on the cerebral circulation before, and one week after, the subarachnoid injection of blood
}

\author{
W FITCH, J D PICKARD, * A TAMURA, $\dagger$ D I GRAHAM \\ From the Wellcome Surgical Institute and the University Departments of Anaesthesia, Neurosurgery and \\ Neuropathology, University of Glasgow, Glasgow
}

SUMMARY Cerebral blood flow (CBF) and mean arterial pressure (MAP) were monitored in six normal baboons and six further animals in which an artificial subarachnoid haemorrhage (SAH) had been induced one week previously. MAP was reduced by the infusion of sodium nitroprusside. In the normal animals with administration of sodium nitroprusside, CBF increased initially but started to decrease as MAP was reduced below $65 \mathrm{~mm} \mathrm{Hg}$ and fell below its baseline value when MAP was less than $50 \mathrm{~mm} \mathrm{Hg}$. In the SAH group, there was no initial hyperaemic response and $\mathrm{CBF}$ fell below baseline values when MAP was reduced below $50 \mathrm{~mm} \mathrm{Hg}$. When, during the infusion of the sodium nitroprusside, MAP was returned to normal using angiotensin, CBF increased above its baseline value. These results suggest that the cerebrovascular effects of sodium nitroprusside are the net result of competition between direct cerebral vasodilatation, falling arterial ${ }^{\circ}$ blood pressure and the degree of impairment of the "autoregulatory" mechanism. Evidence of ischaemic brain damage was found in the arterial boundary zones of both groups of animals.

In view of the widespread clinical use of sodium nitroprusside (SNP) both generally (management of episodes of acute systemic hypertension, ${ }^{12}$ induction of intraoperative hypotension ${ }^{34}$ ) and in neurosurgery ${ }^{5}$ we wished to determine its effects on cerebral blood flow and cerebral oxygen consumption at different degrees of induced hypotension. There is some conflict in the literature over the cerebrovascular effects of SNP partly because previous studies have not examined the whole "autoregulatory" curve. We have examined the following questions: Does SNP have direct effects on the cerebral blood vessels and on cerebral metabolism and how are these modified one week after the subarachnoid instillation of blood? Does SNP predis-

Present addresses: *Wessex Neurological Centre. Southampton General Hospital, Tremona Road, Shirley. Southampton SO94XY, UK. +Department of Neurosurgery, Teiko University School of Medicine, 11-1 Kaga, Zchome, Habashi--ITU, TOK YO 173, Japan.

Received 21 January 1987 and in revised form 10 June 1987 Accepted 26 June 1987 pose to ischaemic brain damage in the boundary zones?

\section{Methods}

The effects of progressive graded decreases in systemic arterial pressure, induced by SNP, on the pressure/flow relationship of the cerebral circulation were investigated in six anaesthetised intact baboons, and in six similar animals one week after the induction of an artificial subarachnoid haemorrhage. This preparation has been described in detail. ${ }^{67}$ In brief, twelve young adult baboons were sedated with phencyclidine, anaesthesia was induced with thiopentone, the trachea intubated and anaesthesia maintained with phencyclidine and nitrous oxide in oxygen. Neuromuscular blockade was produced with suxamethonium and intermittent positive pressure ventilation used. One week previously, six of these animals were anaesthetized with thiopentone and halothane in $70 \%$ nitrous oxide and oxygen. Tracheal intubation was performed and ventilation was controlled. The suprachiasmatic cistern was punctured with a needle passed percutaneously through the optic foramen without enucleation of the orbit. Once a free flow of cerebrospinal fluid had been obtained, $0.75 \mathrm{ml} / \mathrm{kg}$ of the animal's own arterial blood was injected into the subarachnoid space over 30 seconds. After the production of the artificial subarachnoid haemorrhage anaesthesia was discontinued and the animals 
were returned to their cages. No animal developed any neurological deficits and all returned to normal feeding within 24 hours of the procedure.

\section{Hypotensive technique}

Progressive decreases in mean arterial pressure were produced in steps of approximately $10 \mathrm{~mm} \mathrm{Hg}$ by the infusion intravenously (IVAC 531) of increasing amounts of sodium nitroprusside $(0.01 \%$ solution in $5 \%$ dextrose) and, if required, by increases in the concentration infused. Cerebral blood flow (height/area analysis) was measured by external scintillation counting over the right parietal area after the intracarotid injection of 133 Xenon at each step decrease in arterial pressure. Each decrement in pressure took approximately 10-15 minutes to complete and once achieved, MAP was maintained at its new value for at least 5 minutes before the start of each determination of CBF and for the 10 minutes required to complete the measurement. Arterial blood gas tensions and haematocrit were measured during each $\mathrm{CBF}$ estimation. The oxygen contents of samples of arterial and cerebral venous blood (sagittal sinus catheter) were measured with a Lex- $\mathrm{O}_{2}$-Con oxygen content analyser (Albury Instruments Ltd). Cerebral oxygen consumption was calculated from the product of $\mathrm{CBF}$ and the arteriovenous oxygen content difference. Acute increases in systemic arterial pressure were used to assess the physiological integrity of the cerebral circulation, and were produced by the infusion intravenously of angiotensin II amide (Hypertensin, Ciba). Prior to the start of the infusion of SNP, an acute increase in MAP (approximately 30 $\mathrm{mm} \mathrm{Hg}$ ) was induced and a similar acute increase in MAP was produced during the administration of the sodium nitroprusside once MAP had been decreased to around 60 $\mathrm{mm} \mathrm{Hg}$. Any change in $\mathrm{CBF}$ associated with the alteration in MAP was determined

\section{Neuropathology}

At the conclusion of each investigation, the animals were perfusion-fixed and a complete neuropathological examination undertaken. ${ }^{67}$

\section{Statistical analysis}

In the presentation of the results, mean arterial pressure has been calculated as the diastolic arterial pressure plus one third of the pulse pressure, and the values of CBF have been meaned in arterial pressure bins of $10 \mathrm{~mm} \mathrm{Hg}$ : for instance, $79-70 \mathrm{~mm} \mathrm{Hg}, 69-60 \mathrm{~mm} \mathrm{Hg}$. One-way analysis of variance was used to determine whether a significant difference existed between the two groups. Unpaired $t$ tests with the Bonferroni correction were performed to examine the difference between the groups in each bin. Paired $t$ tests were used to compare any increase in CBF with its baseline value.

\section{Results}

Baseline values obtained before the administration of sodium nitroprusside (or angiotensin) were comparable in both groups (table 1), and were similar to values for these indices obtained in previous studies undertaken in baboons using similar techniques of anaesthesia. ${ }^{6-8}$

\section{(A) Induced hypotension}

(1) Intact: Before the commencement of the infusion of sodium nitroprusside MAP ranged from 87 to $113 \mathrm{~mm} \mathrm{Hg}$ (mean, SD $=96 \mathrm{~mm} \mathrm{Hg}, 7$ ) and the control values of CBF varied between 44 and 73 $\mathrm{ml} / 100 \mathrm{~g} \mathrm{~min}^{-1}\left(\right.$ mean, $\left.\mathrm{SD}=59 \mathrm{ml} / 100 \mathrm{~min},{ }^{-1} 12\right)$ at physiological carbon dioxide tensions.

As MAP was decreased progressively by the intravenous infusion of increasing amount of sodium nitroprusside, mean CBF was observed to follow the pattern depicted in fig 1 . It is evident that the administration of sodium nitroprusside induced a degree of cerebral vasodilation: cerebral blood flow increasing progressively until a MAP of approximately 65 $\mathrm{mm} \mathrm{Hg}$ had been achieved, at which point mean CBF was significantly $(p<0.005)$ greater than its baseline value. At lower values of MAP there was a linear pressure/flow relationship with CBF decreasing pari passu with the decreasing arterial pressure. CBF decreased below its baseline value when MAP decreased below about $50 \mathrm{~mm} \mathrm{Hg}$. The lowest values of CBF ranged from $26-33 \mathrm{ml} / 100 \mathrm{~g} \mathrm{~min}^{-1}$ (mean, [SD] $=29 \mathrm{ml} / 100 \mathrm{~g} \mathrm{~min}^{-1}$ [3]) at an average MAP of $25 \mathrm{~mm} \mathrm{Hg} \mathrm{(2).} \mathrm{The} \mathrm{changes} \mathrm{in} \mathrm{CVR} \mathrm{are} \mathrm{illustrated} \mathrm{in}$ fig $1 \mathrm{~b}$.

(2) Subarachnoid haemorrhage: In this group, baseline values of mean CBF ranged from $47-70 \mathrm{ml} / 100 \mathrm{~g}$ $\min ^{-1}\left(\right.$ mean $\left.\pm \mathrm{SD}=56 \mathrm{ml} / 100 \mathrm{~g} \mathrm{~min}^{-1}[ \pm 6]\right)$ at a mean $\mathrm{PaCO}_{2}$ of $41 \mathrm{~mm} \mathrm{Hg}$. Baseline values of mean arterial pressure varied between 83 and $122 \mathrm{~mm} \mathrm{Hg}$ (mean $\pm \mathrm{SD}=104 \mathrm{~mm} \mathrm{Hg}[ \pm 12]$ ).

Despite the administration of similar amounts of sodium nitroprusside, the initial hyperaemic response was virtually non-existent and the small increase in CBF did not differ significantly from the baseline value. As MAP was decreased below $50 \mathrm{~mm} \mathrm{Hg}, \mathrm{CBF}$ decreased below its baseline value (fig 1). The lowest

Table 1 Baseline values (mean $\pm S D$ ) of mean arterial pressure, cerebral blood flow, cerebral metabolic rate for oxygen and arterial carbon dioxide tension

\begin{tabular}{|c|c|c|c|c|}
\hline & $\begin{array}{l}\text { Mean arterial pressure } \\
(\mathrm{mmHg})\end{array}$ & $\begin{array}{l}C B F(H A) \\
(m l m i n-l / l 00 g)\end{array}$ & $\begin{array}{l}C M R O_{2} \\
(\mathrm{mlO} / 02 \mathrm{~min}-1 / 100 \mathrm{~g})\end{array}$ & $\begin{array}{l}\mathrm{PaCO} \\
(\mathrm{mmHg})\end{array}$ \\
\hline $\begin{array}{l}\text { Intact animals }(n=6) \\
\text { SAH animals }(n=6)\end{array}$ & $\begin{array}{r}96 \pm 7 \\
104 \pm 12\end{array}$ & $\begin{array}{l}59 \pm 12 \\
56 \pm 6\end{array}$ & $\begin{array}{l}3.60 \pm 1.2 \\
3.08 \pm 0.7\end{array}$ & $\begin{array}{l}40 \cdot 3 \pm 1 \cdot 0 \\
41 \cdot 0 \pm 1 \cdot 0\end{array}$ \\
\hline
\end{tabular}



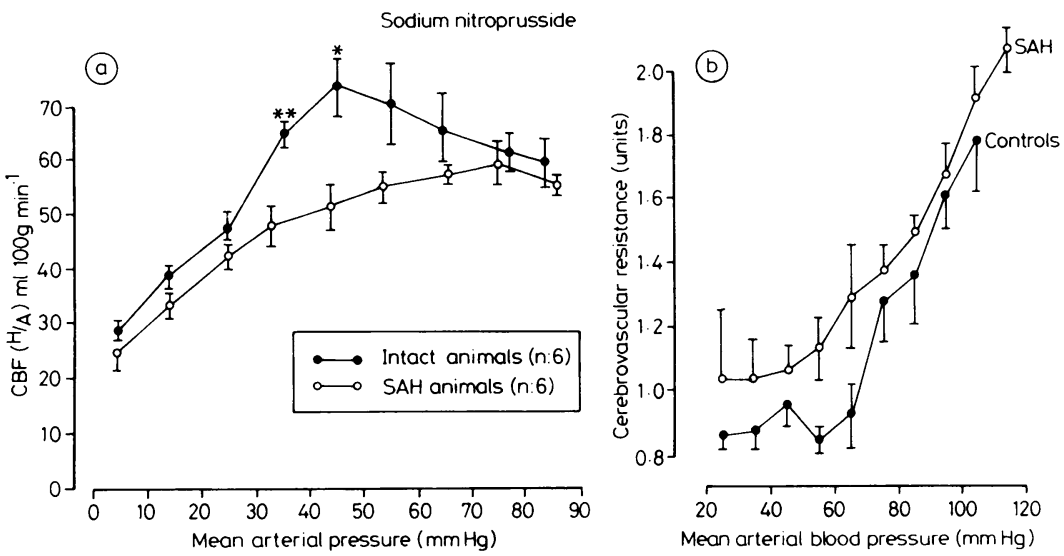

Fig 1 (a) Effects of the administration of sodium nitroprusside on mean arterial pressure and cerebral blood flow. Results (mean $\pm S E M)$ from 6 animals in each group. Significant differences between intact and subarachnoid $(S A H)$ animals. ${ }^{*} p<0 \cdot 0125,{ }^{* *} p<0.005$. (b) Effects of the administration of sodium nitroprusside on Mean Arterial Blood Pressure and cerebrovascular resistance $\left(\mathrm{mmHg} / \mathrm{ml} 100 \mathrm{~g}^{-1} \mathrm{~min}^{-1}\right)$. Results (mean $\left.\pm S E M\right)$ from 6 animals in each group. Two way analysis of variance show's that these two curves are significantly different $(p<0.01)$.

values of CBF ranged from $15-43 \mathrm{ml} / 100 \mathrm{~g} \mathrm{~min}^{-1}$ $\left(\right.$ mean $\left.\pm \mathrm{SD}=29 \mathrm{ml} / 100 \mathrm{~g} \mathrm{~min}^{-1}[ \pm 9]\right)$. The changes in CVR are illustrated in fig 1(b); examination of the changes in CVR do not help to identify separate "inflection" points in the control and SAH groups.

(B) Induced hypertension

(1) Intact: The administration of angiotensin, at baseline values of MAP and CBF (and before the commencement of the nitroprusside infusion) increased MAP acutely by $26 \mathrm{~mm} \mathrm{Hg}( \pm 4)$. CBF did not change significantly from baseline in any animal (mean change $\left.=+3 \mathrm{ml} / 100 \mathrm{~g} \mathrm{~min}^{-1}[ \pm 5]\right)($ fig 2).

The infusion of angiotensin during the continued administration of sodium nitroprusside restored MAP from $57 \mathrm{~mm} \mathrm{Hg}( \pm 3)$ to $92 \mathrm{~mm} \mathrm{Hg}+6(99 \%$ of baseline), and this was associated with a mean increase $( \pm \mathrm{SD})$ in $\mathrm{CBF}$ of $31 \mathrm{ml} / 100 \mathrm{~g} \mathrm{~min}^{-1}( \pm 9)$ $(\mathrm{p}<0.001)$ (fig 2).

(2) Subarachnoid haemorrhage: The administration of angiotensin, before the onset of systemic arterial hypotension, induced an acute increase $( \pm S D)$ in MAP of $31 \mathrm{~mm} \mathrm{Hg}( \pm 5)$. At this value of MAP mean $\mathrm{CBF}$ was $71 \mathrm{ml} / 100 \mathrm{~g} \mathrm{~min}^{-1}( \pm 5)-$ an increase of 15 $\mathrm{ml} / 100 \mathrm{~g} \mathrm{~min}^{-1}( \pm 6) \quad(\mathrm{p}<0.05)$ from its baseline value (fig 2).

During the continuing administration of sodium nitroprusside, and at a MAP $( \pm \mathrm{SD})$ of $56 \mathrm{~mm} \mathrm{Hg}$ $( \pm 6)$, the infusion of angiotensin increased MAP acutely to $112 \mathrm{~mm} \mathrm{Hg}( \pm 5)$. Concomitantly, $\mathrm{CBF}$ ( increased by a mean $( \pm \mathrm{SD})$ of $38 \mathrm{ml} / 100 \mathrm{~g} \mathrm{~min}^{-1}$ $( \pm 15)(\mathrm{p}<0.001)($ fig 2$)$.

(C) Neuropathology

There was evidence of selective neuronal necrosis of

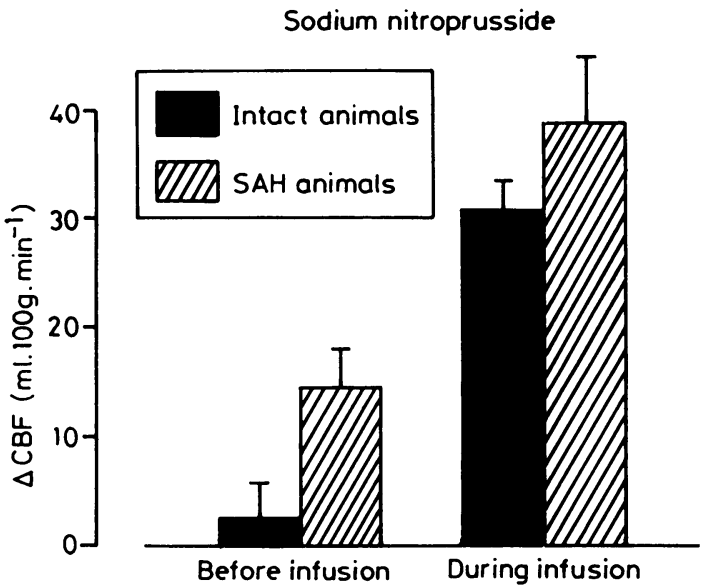

Fig 2 Changes in cerebral blood flow induced by acute increases in mean arterial pressure. Acute increases in mean arterial pressure were induced in hoth groups of animals before the administration of sodium nitroprusside and during the administration of sodium nitroprusside once mean arterial pressure had heen decreased to around $60 \mathrm{mmHg}$. 
the type seen in $40 \%$ formaldehyde, glacial acetic acid, absolute methanol 1:1:8 material fixed in five of both the intact and subarachnoid haemorrhage groups of six animals. No lesions were identified in one animal from each group. The ischaemic cell process was restricted mainly to the arterial boundary zones with lesions mainly between the distributions of the anterior and middle cerebral arteries (figs $3 \& 4$ ). In addition, in the intact group, one animal had lesions in the striatum and another had lesions in the thalamus. One subarachnoid haemorrhage animal had small foci of necrosis in the Sommer sector of each Ammon's Horn. In the subarachnoid haemorrhage group, some residual blood was observed in the subarachnoid space, and small amounts of haemosiderin were seen in phagocytes.

(D) Cerebral metabolic rate for oxygen

There was no substantial changes in the cerebral metabolic rate for oxygen in either group (table 2). The only changes observed were related to the final two measurements of CBF, and hence, to the two lowest values of MAP by which point $\mathrm{CMRO}_{2}$ had decreased by approximately $20 \%$ and $18 \%$ from baseline in the intact and subarachnoid haemorrhage groups, respectively.

\section{Coronal sections of monkey brain}
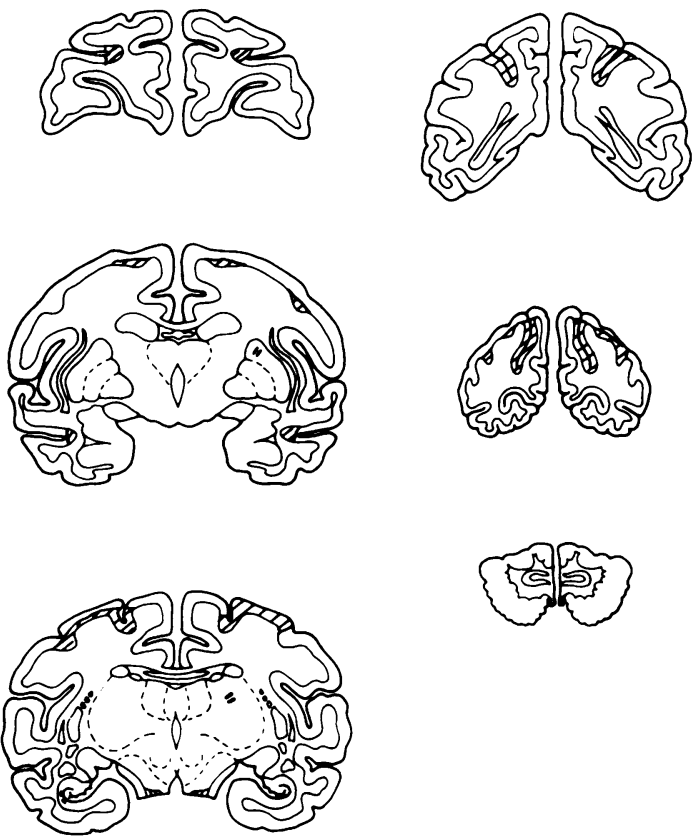

Fig 3 Intact animal: diagrammatic representation of coronal sections of brain. Hatched areas depict those with morphological evidence of ischaemic cell change.
Discussion

In the normal animals, care was taken to demonstrate that the cerebral circulation had normal "autoregulatory capacity"; as confirmed by maintenance of normal CBF with moderate elevations in arterial blood pressure with angiotensin II prior to administration of sodium nitroprusside. Furthermore we have examined the complete autoregulatory curve. Our results confirmed that in the normal baboon, SNP produces an initial hyperaemia despite a moderate decrease in MAP, and that this hyperaemia was not due to metabolic stimulation as there is no change in cerebral oxygen consumption (our study is unusual in the literature for reporting values for $\mathrm{CMRO}_{2}$ in such experiments). There has been some controversy in the literature as to whether such a hyperaemia exists ${ }^{910}$ or not. ${ }^{15-18}$ Certainly, both experimentally ${ }^{11}$ and in man ${ }^{12-14}$ intracranial pressure increases with small doses of SNP. In man, there was no significant change in $\mathrm{CBF}$ at $50 \mathrm{~mm} \mathrm{Hg}$ compared with baseline value but the intermediate steps were not examined. ${ }^{19}$

SNP would appear to impair "autoregulation", that is, the ability of the cerebral circulation to main-

\section{Coronal sections of monkey brain}
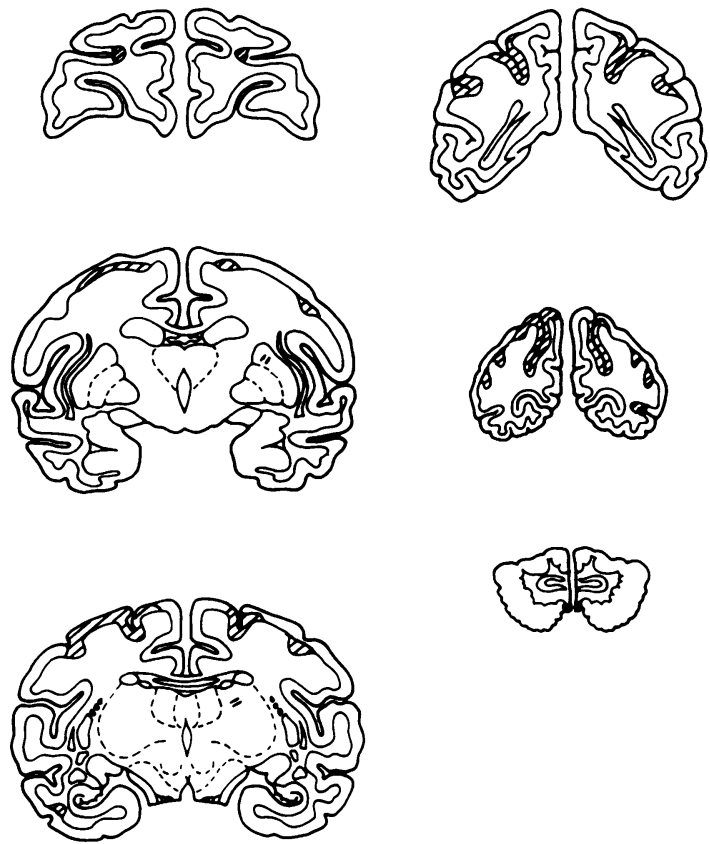

Fig 4 Suharachnoid animal: diagrammatic representation of coronal sections of brain. Hatched areas depict those with morphological evidence of ischaemic cell change. 
Table 2 Values of cerebral oxygen consumption (mean $\pm S D$ ) at different levels of mean arterial blood pressure induced by sodium nitroprusside both in intact animals and one week following subarachnoid haemorrhage

\begin{tabular}{|c|c|c|}
\hline \multirow{2}{*}{$\begin{array}{l}\text { Mean arterial } \\
\text { pressure } \\
\text { range } \\
(\mathrm{mmHg})\end{array}$} & \multicolumn{2}{|c|}{ Cerebral oxygen consumption $\left(\mathrm{mlO} \mathrm{O}_{2} 100 \mathrm{~g}^{-1} / \mathrm{min}\right)$} \\
\hline & $\begin{array}{l}\text { Intact } \\
(n=6)\end{array}$ & $\begin{array}{l}\text { Post-SAH } \\
(n=6)\end{array}$ \\
\hline $\begin{array}{c}100-109 \\
90-99 \\
80-89 \\
70-79 \\
60-69 \\
50-59 \\
40-49 \\
30-39 \\
20-29\end{array}$ & $\begin{array}{l}3.54 \pm 1.06 \\
3.89 \pm 1.42 \\
3.37 \pm 1.24 \\
3.90 \pm 1.44 \\
3.99 \pm 1.37 \\
3.83 \pm 1.20 \\
2.99 \pm 1.03 \\
2.98 \pm 0.88 \\
2.51 \pm 0.86\end{array}$ & $\begin{array}{l}2.95 \pm 0.58 \\
3.58 \pm 0.67 \\
3.29 \pm 0.41 \\
3.08 \pm 0.50 \\
2.97 \pm 0.31 \\
3.03 \pm 0.61 \\
3.03 \pm 0.61 \\
2.75 \pm 0.62 \\
2.19 \pm 0.59\end{array}$ \\
\hline
\end{tabular}

tain constant flow with changing perfusion pressure. Return of MAP to normal from $60 \mathrm{~mm} \mathrm{Hg}$ using angiotensin II during constant SNP infusions, results in a considerable increase in CBF. If SNP was not a direct vasodilator and had no effect on the autoregulatory mechanism, then return of MAP to normal would not produce any increase in CBF. This "pressor test" was originally reported by Ivankovich in $1976 .{ }^{9}$ Although the direct perivascular injection of angiotensin II induces significant vasoconstriction of pial arterioles, systemic administration had no effect on global CBF. ${ }^{20}$ However, the systemic administration of angiotensin II may have a vasoconstrictor effect in parts of the cerebral circulation not insulated by the normal blood brain barrier. As angiotensin II has either no effect or contracts cerebrovascular smooth muscle in vivo, the increase in CBF with angiotensin in this study cannot be ascribed to its direct vascular effects. It might be argued that these effects were the result of the accumulation of toxic metabolic products of sodium nitroprusside. The fall in $\mathrm{CMRO}_{2}$ at the lowest levels of arterial pressure might reflect cyanide toxicity. In total, a number of animals received more than the accepted maximum dose of SNP $(0.5 \mathrm{mg} / \mathrm{kg} /$ hour $)$. However, most of the administered dose was utilised to obtain, and then sustain, the lowest value of MAP. The amounts of sodium nitroprusside required to produce MAPs of around $60 \mathrm{mmHg}$ were approximately $0.2 \mathrm{mg} / \mathrm{kg} / \mathrm{hour}$, and $0.17 \mathrm{mg} / \mathrm{kg} /$ hour in the intact and subarachnoid haemorrhage groups, respectively. We conclude that sodium nitroprusside is not only a cerebral vasodilator but that it impairs the ability of the normal cerebral circulation to respond physiologically to increases or decreases in MAP. A similar conclusion was reached by Ivankovich $e t$ al in the goat. ${ }^{9}$ Under these circumstances, the term "autoregulation" is a misnomer: $\mathrm{CBF}$ is determined by the interplay between the induced alterations in perfusion pressure, the direct cerebral vasodilatory actions of the drug and the degree of impairment of the autoregulatory mechanism. The direct effects of sodium nitroprusside on the contractile mechanism of vascular smooth muscle may alter the intrinsic reactivity of the cerebral blood vessels. It is not possible to validate the presence or impairment of "autoregulation" by altering mean arterial pressure with drugs which have direct effects of vascular smooth muscle. Furthermore, the precise pattern of the pressure flow relationship differs depending on the drug employed to decrease MAP. In the intact cerebral circulation, CBF is maintained at or above the baseline value until MAP is reduced below $50 \mathrm{mmHg}$ with SNP. In a previous study from this laboratory, hypotension induced by the combination of halothane $(0.5 \%)$ and SNP did not increase CBF at MAP higher than $45 \mathrm{mmHg}$. However, halothane not only reduces the dose of SNP required to produce any level of hypotension but also attenuates the direct cerebral vasodilator effects of SNP. ${ }^{9}$

As documented fully in the earlier papers ${ }^{67}$ these animals are neurologically intact one week after the subarachnoid injection of blood, have normal intracranial pressure with no ischaemic cell change or ultra-structural damage to the cerebral arteries. Despite this rather mild insult compared with that seen in many patients, both the ability of the cerebral circulation to maintain $\mathrm{CBF}$ constant with moderate $\mathbb{\Omega}_{\Omega}^{\mathbb{Q}}$ halothane-induced hypotension or angiotensininduced hypertension and the reactivity to hypercapnia and hypoxia are impaired one week after a subarachnoid haemorrhage.

Autoregulation to halothane-induced hypotensions during surgery for aneurysmal subarachnoid haemorrhage is impaired in about $25 \%$ of patients who had a normal conscious level and no neurological signs pre-operatively. ${ }^{22}$ These present studies confirm that, following subarachnoid haemorrhage, CBF does not remain constant but increases with moderate hypertension induced with angiotensin II prior to administration of sodium nitroprusside. There is no initial hyperaemia with SNP in the subarachnoid haemorrhage group, but CBF does not start to decrease significantly until MAP decreases below around $50 \mathrm{mmHg}$. The risk of development of delayed cerebral ischaemia after clipping of the aneurysm is greatly increased in those patients whose CBF decreases with moderate hypotension induced by halothane or trimetaphan. In a small series of patients the prognosis post-operatively was worse in those in whom CBF did not increase with SNP-induced hypotension but either remained constant or decreased. ${ }^{23}$ Our experimental results confirm that it is abnormal for cerebral blood flow not to increase with moderate hypotension induced with sodium nitroprusside. 
In contrast to our previous studies ${ }^{7}$ with halothane-induced hypotension where no ischaemic cell change was found using a similar experimental protocol (lowest MAP value: $26 \mathrm{mmHg}$ in the intact group and $32 \mathrm{mmHg}$ in the subarachnoid haemorrhage group), ischaemic cell damage was found both in the intact and subarachnoid haemorrhage groups after SNP (lowest MAP: $25 \mathrm{mmHg}$ intact; $24 \mathrm{mmHg}$ subarachnoid haemorrhage), despite global $\mathrm{CBF}$ remaining at or above $25 \mathrm{mls} / 100 \mathrm{gms} / \mathrm{min}$. The detection of ischaemic cell change avoids the sampling errors inherent in techniques such as the determination of micro-regional $\mathrm{CBF}$ and the measurement of changes in the brain concentrations of extracellular ions. The pattern of ischaemic cell change noted in the present study mirrors that of the changes to the blood brain barrier demonstrated recently by Ishikawa and colleagues. ${ }^{24}$ In addition, regional variation in the cerebrovascular response to SNP was found in the goat. $^{25}$

The net effects of SNP on global cerebral blood flow are the results of a complex interaction and the apparent maintenance of CBF above a MAP of $50 \mathrm{mmHg}$ should not be taken to imply that physiological reactivity is normal. Whilst the ischaemic threshold of the brain may not be altered, the anaesthetist cannot depend on the physiological integrity of the cerebral circulation to protect the brain from the effects of inadvertent or uncontrolled decreases in arterial pressure. We do not know how long the cerebrovascular effects of SNP take to reverse after it is stopped.

A preliminary report of this work was presented to the Symposium on the Pathophysiology and Pharmacotherapy of Cerebrovascular Disorders in Tubingen (1980). Financial support was provided by the Medical Research Council. The authors are very grateful to the nursing and technical staff at the Wellcome Surgical Institute for their skill and care with these studies.

\section{References}

1 Page IH. Corcoran AC. Duston HP: Cardiovascular actions of sodium nitroprusside in animals and hypertensive patients. Circulation II 1956;188-98.

2 Palmer RF. Lasseter KC. Sodium nitroprusside. $N$ Engl J Med 1975;292:294-7.

3 Moraca PP. Elmars MB. Hale DE, Wasmith CE. Poutasse EF. Clinical evaluation of sodium nitroprusside as a hypotensive agent. Anesthesiologi 1962:23:193-199.

4 Taylor TH. Styles M, Lamming AJ. Sodium nitroprusside as a hypotensive agent in general anaesthesia. $\mathrm{Br} J$ Anaesth 1970;42:859-63.

5 Rudehill A. Gordon E. Lagerkranser M. Sodium nitroprusside as a hypotensive agent in intracranial aneurysm surgery. Acta
Anaesth Scand 1979:23:404-10.

6 Boisvert DPJ, Pickard JD, Graham DI, Fitch W. Delayed effects of subarachnoid haemorrhage on cerebral metabolism and the cerebrovascular response to hypercapnia in the primate. $J \mathrm{Neu}$ rol Neurosurg Psychiatry 1979:42:892-98.

7 Pickard JD, Boisvert DPJ, Graham DI, Fitch W. Late effects of subarachnoid haemorrhage on the response of the primate cerebral circulation to drug-induced changes in arterial blood pressure. J Neurol Neurosurg Psychiatry 1979;42:899-903.

8 Fitch W, McGeorge AP, Mackenzie ET. Anaesthesia for studies of the cerebral circulation: a comparison of phencyclidine and Althesin in the baboon. Br J Anaesth 1978;50:985-91.

9 Ivankovich AD, Miletich DJ, Albrecht RF, Zahed B. Sodium nitroprusside and cerebral blood flow in the anesthetized and unanesthetized goat. Anesthesiology 1976;44:21-26.

10 Candia GJ, Heros RC, Lavyne MD. Effect of intravenous sodium nitroprusside on cerebral blood flow and intracranial pressure. Neurosurg 1978;3:50-52.

11 Morris PJ, Todd M, Philbin D. Changes in canine intracranial pressure in response to infusions of sodium nitroprusside and trinitroglycerin. Br J Anaesth 1982;54:991-5.

12 Turner JM, Powell D, Gibson RM. Intracranial pressure changes in neurosurgical patients during hypotension induced with sodium nitroprusside or trimetaphan. $\mathrm{Br} J$ Anaesth 1977:49:419-25.

13 Cottrell JE, Patel K. Turndorf H, Ranshoff J. Intracranial pressure changes induced by sodium nitroprusside in patients with intracranial mass lesions. J Neurosurg 1978;48:329-331.

14 Marsh ML. Shapiro HM, Smith RW. Changes in neurologic status and intracranial pressure associated with sodium nitroprusside administration. Anaesthesiology 1979;51:336-8.

15 Stoyka WW, Schutz H. The cerebral response to sodium nitroprusside and trimetaphan controlled hypotension. Can Anaesth Soc J 1975;22:275-283.

16 Waltz AG. Effect of blood pressure on blood flow in ischemic and in nonischemic cerebral cortex. Neurology 1968;18:613-21.

17 Brown FD, Crockard HA, Johns LM. Mullan S. The effects of sodium nitroprusside and trimetaphan camsylate on cerebral blood flow in Rhesus monkeys. Neurosurgery 1978:2:31-33.

18 Brown FD, Hanlou K, Crockard HA. Mullan S. Effect of sodium nitroprusside on cerebral blood flow in conscious human beings. Surg Neurol 1977;7:67-70.

19 Larsen R. Teichmann J, Hilfiker O, Busse C, Sonntag H. Nitroprusside-hypotension: Cerebral blood flow and cerebral oxygen consumption in neurosurgical patients. Acta Anaesth Scand 1982:26:327-30.

20 Acar U. Pickard JD. Angiotensin and pial arterioles: Implications for the study of CBF autoregulation. In: Betz E. Grote J, Heuser D. Wullenweber R, eds Pathophysiology and Pharmacotherapy of Cerehrovascular Disorders. New York, Verlag Gerhard. 1980;37-38.

21 Fitch W. Ferguson GG. Sengupta D. Garibi J, Harper AM Autoregulation of cerebral blood flow during controlled hypotension in baboons. $J$ Neurol Neurosurg Psychiatry 1976;39:1014.

22 Pickard JD. Matheson M. Patterson J, Wyper DJ. Prediction of late ischaemic complications after cerebral aneurysm surgery by the intraoperative measurement of cerebral blood flow. $J$ Neurosurg 1980:53:305-8

23 Powell MP. Coakham HB. Cummins BC. Griffith HB. Silver IA. The intraoperative measurement of cerebral blood flow and cortical oxygen tension during aneurysm surgery: The response to sodium nitroprusside and nimodipine. $J$ Cereh Blood Flow Metah 1983:3:S53-S54.

24 Ishikawa T. Funatsu N. Ikamoto K. Takeshita H. McDowall DG. Blood-brain barrier function following drug-induced hypotension in the dog. Anesthesiology 1983:59:526-31.

25 Miletich DJ. Gil KSL, Albrecht RF, Zahed B. Intracerebral blood flow distribution during hypotensive anaesthesia in the goat. Anesthesiology 1980:53:210-4. 